\title{
Article \\ Crossing Boundaries: Acts of Citizenship among Migrant Youth in Melbourne
}

\author{
Fethi Mansouri * and Maša Mikola \\ Centre for Citizenship and Globalisation, Deakin University, 221 Burwood Hwy, Burwood, Victoria 3125, Australia; \\ E-Mails: fethi.mansouri@deakin.edu.au (F.M.), masa.mikola@rmit.edu.au (M.S.); Tel: +61-3-924-43914 (F.M.); \\ Fax: +61-3-924-46755 (F.M.) \\ * Corresponding author
}

Submitted: 2 August 2013 | In Revised Form: 2 May 2014 | Accepted: 2 May 2014 | Published: 20 August 2014

\begin{abstract}
This paper focuses on how migrant youth in Melbourne with experience of direct or indirect migration negotiate crosscultural engagements and tensions between family, community and the greater society in which they are supposed to participate as political subjects. It examines whether the meaning and interpretation of citizenship in Australia allows migrant youth to act as full and active citizens with all the contradictions and difficulties inherent in acting as "a bridge between two worlds". By voicing the personalised journeys of young people dealing with uneasy questions of displacement, identity and belonging, this paper examines the complex ways through which migrant youth negotiate and in some cases bridge intercultural tensions within a multicultural society.
\end{abstract}

\section{Keywords}

belonging; citizenship; multicultural youth; participation; social networks

\section{Issue}

This article is part of the special issue "Migrant Youth, Intercultural Relations and the Challenges of Social Inclusion", edited by Professor Fethi Mansouri (Deakin University, Australia) and Dr. Anna Halafoff (Deakin University, Australia).

(C) 2014 by the authors; licensee Cogitatio (Lisbon, Portugal). This article is licensed under a Creative Commons Attribution 4.0 International License (CC BY).

\section{Introduction}

A number of policy initiatives in Australia have sought to improve the societal conditions of young people in general and migrant youth in particular. This can be seen in a number of recent reports by Government agencies that all focus on young people, including: "Investing in Australia's young people" (Australian Office for Youth, 2009); the "State of Australia's Young People" (Muir et al., 2009); the "National Strategy for Young Australians" (Australian Government, 2010); or the "Melbourne Declaration on Educational Goals for Young Australians" (MCEETYA, 2008). Furthermore, the Australian Youth Forum was established in 2008, while the Victorian Government launched the "Youth Statement: Engage, Involve, Create" initiative in 2012. There are also numerous local and regional youth strategies.
These strategies, as well as other so-called early intervention programs, suggest that many young people are "at risk", that they are "disengaged", that they need to "engage" in education or employment, be "involved" in their communities and decision-making processes and "create" change, enterprise and culture (Victorian Government, 2012). Migrant and refugee youth have been included in these strategies through an emphasis on promoting cultural diversity, tolerance, anti-discrimination and anti-racism measures. Nevertheless, a coherent national strategy pertaining directly to migrant youth is yet to be established, ignoring repeated calls by experts and service providers working with this demographic group. This, despite the fact that migrant youth have been positioned as "one of the assets" of multiculturalism (Centre for Multicultural Youth, 2012) and their social integration as well as their symbolic incorporation 
into the host society have been cited as key indicators of their wellbeing (Sampson \& Gifford, 2010; Wyn \& Woodman, 2006).

The article focuses on migrant youth who are loosely defined as either African or Arabic-speaking and who are living in Melbourne. As the most recent Australian Bureau of Statistics Census data (2011) show, Melbourne is a relatively "young" city with 40 per cent of its population 29 years of age or younger, among them 12.2 per cent are between the ages of 15-24 (Muir et al., 2009). ${ }^{1}$ Furthermore, 36.7 per cent of the population of Greater Melbourne were born overseas, and there are more Melbournians with both parents born overseas than those whose parents were born in Australia (Australian Bureau of Statistics, 2011). But the traditional migration that has shaped Melbourne and Australia for many decades has witnessed a demographic shift in more recent times with the arrival of African entrants, most of whom are from war-torn countries in the Horn of Africa region. This new cohort of migrants has posed new challenges for youth programs and settlement service providers; particularly during their early stages of settlement in Australia.

Against this highly diverse cultural setting, this paper examines the networking practices of migrant youth: the way they create and sustain connections between their homes/families/communities on the one hand, and the socio-political sphere of Australian multicultural society, as articulated through policies, on the other. It examines empirically and conceptually specific ways through which migrant youth become "everyday makers" (Bang, 2005) and "actors of citizenship" (Isin, 2009; Isin \& Nielsen, 2008).

\section{Youth Participation and Citizenship}

In the Australian context, following a classic liberal view of citizenship most readily represented by $\mathrm{T}$. $\mathrm{H}$. Marshall (1950), the concept of participation most often relates to the idea that one needs to be involved in the workforce to become an active citizen (ColicPeisker, 2009) and that one's participation is a reflection of democratic practice (Bessant, 2004). When translated to the context of youth participation, policy documents often focus on youth's transition from adolescence into adulthood, as this is assumed to be the time when young people's capacities can be enhanced by their participation in broader society, in their transition towards "full" and active citizenship.

There has been an increase in the number of youth participation programs in Australia, using either youth development or youth involvement approaches ${ }^{2}$. Both

\footnotetext{
${ }^{1}$ In Australia, young people aged 12 to 24 represent nearly 20 per cent of the Australian population and 28 per cent of all households contain a young person.

${ }^{2}$ In both of these approaches, youth is regarded as an entity
}

approaches encourage positive engagement between young people and institutions on all levels of governance. But whilst youth development approaches have been utilised in Australia predominantly at the federal level and have focussed on nurturing key skills and competencies in particular during transitional periods, youth involvement approaches have been more focussed on local, state and community levels, and emphasise links between individuals, their active participation and broader social outcomes.

Even though youth participation approaches promote principles of equality, justice and young people's rights to participate (Bessant, 2004), in practice they still tend to regard individuals as "consumers in informing program or policy development" (Bell, Vromen, \& Collin, 2008, p. 33) and their involvement in participatory projects only rarely influences actual public decision-making (Kirby \& Bryson, 2002). What is also not often acknowledged in youth participation and citizenship programmes is that even though political participation for young people is possible and should be encouraged, there are still structural limitations that they face in achieving what is considered full citizenship. For instance, young people under 18 are unable to vote in Australia, their freedom of speech and movement is often limited in public spaces, and the law permits age discrimination in the labour market, which means that people under 18 can be paid lower wages and work in more precarious conditions (Bessant, 2004, pp. 393397). There is also little consistency in the ways in which participation is understood among academic and policy literature (Bell et al., 2008; Matthews, Limb, \& Taylor, 1998/1999). This has, as Bell et al. argue, "serious implications for the subsequent recognition of young people's capacity or entitlement to shape policy outcomes that will affect their everyday lives" (Bell et al., 2008, p. 29).

Naturally, participation programmes give more attention to those young people who are interested in being actively engaged in formal institutions, and not to those who oppose the idea of formal participation, even though the latter may still engage in self-organised groups and activities. It should be noted here that formal participation relates to the nature of engagement rather than the activity itself. To this end, many African youth have engaged in music and sporting activities accessed formally through local agencies and clubs. But irrespective of the modality of access, youth participation programmes focus on positive relationships, not negative responses to the institutions and policies in place. Young people who voice their opinions against

with certain distinguishable characteristics. A special category of culturally and linguistically diverse (CALD) youth is often incorporated into these programs, and such categories, though sometimes useful, are often vague in their generalisation of a vast array of people which can render such a category diffuse. 
their treatment by authorities or disagree with existing laws and regulations, such as being regularly stopped and searched by police (Smith \& Reside, 2010), do not get much coverage in representative case studies of youth programmes. Besides, young people from culturally and linguistically diverse (CALD) backgrounds are most often seen in youth participation and engagement programs as a homogenous group that share universal youth participation opportunities. Their different experiences of exclusion and disadvantage which, as some critics argue, "should shape targeted youth participation strategies" (Bell et al., 2008), are not always taken into account.

Furthermore, youth participation approaches commonly used in Government programmes aimed at strengthening political participation understate the fact that the arena of the "political participation" is utilised by a diverse group of migrant youth in a much broader manner than it is acknowledged in traditional participatory theories based on representative democracy concepts (Milbrath \& Goel, 1977; Verba \& Nie, 1972). Whereas representative democracy concepts rely on classic indicators of political involvement, such as voting, signing petitions, sending letters to politicians, attending meetings, etc., they do not look at other types of non-institutionalised involvement. They overlook the fact that young people's political involvement and participation does not happen exclusively within the framework of formalised institutions, be they supported by the community or the Government (Harris, Wyn, $\&$ Younes, 2010). Young people participate and engage in different ways to adults (Vinken, 2005), in ways that differ from conventional political participation (Dalton, 2006, p. 64).

Inherent to this is a challenge and a problem in the way we, as a society, understand and define what falls under the umbrella of the "political". Political acts are often concerned with seeking to change public views and policies (Vromen, 2003, p. 86). This idea, however, of "being political" is normally reduced to one becoming a "member of a party, union or campaign for institutionalised arenas"; "making a donation, volunteering time, boycotting products, attending rallies" are in this context not regarded as political acts (Vromen, 2003, p. 86). Young people, including young migrants, participate in an environment that is increasingly susceptible to engagement in new social movements and alternative avenues of protest politics (Norris, 2002). In this context, young people's acts such as self-mobilisation, protest and voluntary community engagement should be seen as demands for recognition, which require modification of the ideas about who are political agents and what constitutes active participation.

Relying on this critical context, Isin and Nielsen (2008, p. 39) talk about "acts of citizenship" which they define as "( $t$ )hose acts that transform forms (orientations, strategies, technologies) and modes (citizens, strangers, outsiders, aliens) of being political by bringing into being new actors as activist citizens (claimants of rights and responsibilities) through creating new sites and scales of struggle". These sites can exist outside of formal institutions and can be decided on an individual, ad hoc and project basis, revealing the spontaneous, everyday character of many of these acts (Bang, 2005).

Against this theoretical discussion, political participation and social engagement of migrant youth are defined as complex processes which advocate for a more profound and realistic recognition of the fluid processes, recognising the significance of the roles youth play in bridging cultural and ethnic divides. Not only youth's involvement in their communities and decision-making processes, but their creation of their own ways of political participation is regarded as a vital act of citizenship, integral to the opening up of a necessary bilateral dialogue between both diverse ethnic communities as well as Australian society in general (such exchange is often sadly lacking). Young migrants' ability to actively disrupt this dominant, one-way, discourse is of critical importance. This is especially the case as such dominant discourses often position them as indebted and in need of assimilation and immersion whilst denying their agentive voice in the ongoing conversation about national identity.

\section{Acts of Citizenship among "Everyday Makers"}

In their critique of Robert Putnam's theory (2000)about weakening social ties, and the consequent eroding of trust between people and political authorities, resulting in poorer political participation outcomes that can be increased only by involvement in voluntary organisations-Henrik Bang and Eva Sørensen (1999) argue that Putnam's theory is empirically flawed, because it prevents us from analysing "central aspects of societal life today" by separating social and political capital. They introduce a concept that, as they contend, contradicts Putnam's theory-a concept of the "everyday maker" - which "represents a new form of political engagement, which attempts to combine individuality and commonality in new relations of self- and co-governance" (Bang \& Sørensen, 1999, p. 325). Everyday makers are "those who consider politics as lived experience" (Bang, 2009, p. 119), among them many young people, who are "project-oriented" and "do not feel defined by the state" (Bang, 2005, p. 167). They can be mobilized if "governance initiatives can open up political spaces for young people to organize around and articulate the issues that concern them" (Marsh, O'Toole, \& Jones, 2007). New generations have the capacity to invent new forms of citizenship (Vinken, 2005, pp. 148-149). As much as the reasons for their involvement in activities, networks and projects rest in the idea that "it is for a good cause", young people get 
involved also because "you get something out of it yourself". As Bang (2005, p. 169) explains:

(e)veryday makers consider their lay knowledge embodied in their activities. They do not separate knowledge and practice, which is why they insist on deciding themselves where to 'hit' and when to 'run', whether alone or in cooperation with others.

Participation of "everyday makers" needs to be motivated by significant personal outcomes. In this way, they are personally engaged, but they may be seen also as individualistic, atomised and market-oriented.

"Active citizenship" approaches often neglect that citizenship is not only about social practices and norms, but also about meanings and identities. People need to feel a certain sense of belonging in order to be "good", "active" citizens. Youth participation programs are often "problem-oriented", focusing on the periods of transition when young people are presumably most often at risk of disengagement. They do not acknowledge plurality of forms of engagement among migrant youth or their motivations for engagement. As Isin $(2000$, p. 5) contends, being politically engaged in a globalized, intersectional and stratified world may reveal loyalties not only to the government in the classical normative sense, but to different political communities, governing bodies and domains, such as the workplace, shopping mall and Internet. These can all signify fields of struggle; "an arena in which relations linking individuals to their wider community, social and political contexts are continually discussed, reworked and contested" (Hall, Williamson, \& Coffey, 2000). Additional layers of citizenship participation (Yuval Davis, 1997, 2007) can become embodied in more local contexts, such as local arts or human rights groups, or ethnic community organisations and family networks (Desforges, Jones, \& Woods, 2005), or they are rescaled upwards above the nation-state and in the process become more transnational or global.

\section{Methodology and Research Sample}

The paper draws on a small section of a large pool of data gathered as a part of an Australian Research Council Linkage research project which examined social networks, issues of belonging and active citizenship among migrant youth in Melbourne and Brisbane (2009-2012). Data used in this paper has been gathered in two focus groups organised in October 2011 with fifteen migrant youth in Melbourne.

The young people in the two focus groups were born overseas, they were 18 to 23 years of age, and were classified as either of African heritage or of Arabic-speaking background ${ }^{3}$. Both focus groups were in-

3 In some cases, the two categories of African and Arabic- ternally diverse with a range of age distribution, different countries of origin and variant period of settlement. Participants who indicated religious affiliations were mostly Christian or Muslim. There was a slight over-representation of female participants. The African participants were relatively recent arrivals and mostly former refugees originating from Sudan, Eretria and Ethiopia. This contrasts with the Arabic-speaking group which included mainly Iraqi youth. The focus groups were organised in the context of a "Young Leaders Forum" event, where recruited participants were expected to discuss their views of effective leadership, role-modelling and issues affecting their respective communities. They discussed these issues with service providers and academics involved in the project, and they received certificates for participation at the conclusion of the forum. Two successful and active young leaders in Victoria, involved in advocacy and consultancy as well as global leadership programs, cross-cultural relations and volunteering were invited to participate at the forum as guest speakers. Young people who were involved in focus group discussions had for the most part already well-formed views on participation, representation and community work in Australia and were willing to exchange these views. A majority of participants felt that they play an important role in highlighting youth issues and challenges as experienced in their particular communities. Young people in Arabic-speaking and African focus groups were interested in the concept of leadership and thought of it as an important quality to have as a young person in Australia.

Though in some cases problematic, the deployment of the group categories (Arabic-speaking, African) in the design of the project, nevertheless offered pathways to the creation of discursive spaces and provided context for arguments and counter-arguments about media generated stereotypes and essentialised identities. What was observed throughout the discussions was that limitations of categories, including ethnic and/or linguistic backgrounds, have practical consequences for many young people, even if these categories denote abstract constructions.

Some participants openly contested the idea of fixed categories. Yet, when they were asked to join one of the discussion groups they decided to self-select and participate in the relevant group with relative ease. The focus groups were followed by a general discussion which reflected differences in experiences already pointed out in the focus groups. Most of the participants in the focus groups have been living in Melbourne for 5-10 years, and none were born in Australia. Most of the participants were active in mainstream as well as community specific activities. Their family circumstances were various: some arrived in Australia

speaking overlapped as with the case of some participants from the Horn of Africa who also spoke Arabic. 
as a part of the Australian humanitarian and refugee program with both or one of their parents, while others came to Australia with other relatives or as unaccompanied minors. Some African participants settled in Australia after spending considerable periods of time in refugee camps outside of their country of birth, as is the case with Sudanese youth for instance who spent several years in Egypt before arriving in Australia. Participants in focus groups lived in different parts of Melbourne and most of them highly valued formal education and were enrolled in tertiary education institutions.

\section{5. "Stepping Out" and "Tuning" Oneself}

Overall, the participants in the focus groups indicated a desire to network cross-culturally and outside of their immediate, culturally specific environments. They strongly expressed, in various ways, the desire to "step out" of their familiar and familial environments and to be involved in a wider globally-oriented space; or as one participant in the focus group put it "to tune yourself" to the world you live in is a necessary path towards constructive dialogues.

Focus group participants manifested their participation in the wider political sphere in various ways. Some of them were members of youth-based and youth-run organisations and networks (for instance, Western Young People's Independent Network, Ethnic Youth Council or the Multicultural Advocacy Network), some were involved in producing media content (for instance for $3 Z Z Z$ community radio or social media sites), and some were involved in community events, local councils, music (especially hip hop) and similar cultural activities. Their sites of citizenship activities included also educational institutions, especially the university. One participant spoke about his role as a student of social work as he had deliberately chosen to study for a social work degree in the hope of contributing to positive social change among migrant youth.

The desire to network and influence public opinion that young people referred to in the focus groups was accompanied by a strong sense of place and location (being of Ghanaian, Somali, Oromo, Iraqi background, but living in Australia), which was often their immediate response to feelings of displacement and dislocation. Location and place, in this sense, were derived from the respondents' culturally specific identities. Their desires and acts of "stepping out" depended on the extent to which they were ready to embrace difference, and on their willingness to be identified as "different", not only in terms of culture, language or accent or religion, but also in terms of their unique life experiences and their consequent world views.

Harmonious and sometimes antagonistic relationships between openness for difference and pursuit of recognition unveiled their struggles for belonging in multicultural Australia. One point of a discussion in the
African focus group centred on a tendency to "tailor the culture" of migrants in Australia. As one of the participants explained:

We have to make our culture as barbaric or as acceptable for them to fit into their own perception of who we are and for me I always have to tailor my identity. It's a conscious decision. Like with the question of where I'm from. I try to project or...they're trying to gain a level of understanding where I'm from. And I'm Oromo and no African even knows where that is. And that's fine, I accept that. [...] And, another thing is...As Muslims we tailor our names to people. It's very hard for people to say 'kha', that throaty, disgusting, flaming sound, so Khamal becomes Jimmy, Ali becomes Al...just to fit into their own linguistic understanding of who we are.

Such realisations and challenges drove many young migrants to form groups, get exposed and seek recognition for their own ethno-specific voices. They refused to remain fixed in their roles as contributors of these voices by challenging traditional forms of ethnic representation in Australia, composed of elected community representatives voicing concerns of their entire communities. Rather, they adopted flexible approaches to their participation, as well as representation. They were involved in community events, but they were also participating in school activities, faith-based groups and choirs, they were forming music and dance groups, or played soccer. Some of them participated also in more traditional forms of ethnic community engagement, for instance in local or national boards and councils (multicultural, ethnic or youth-based) or in national youth leadership programmes. These various activities were interconnected and could exist simultaneously; they did not cancel each other out.

Participation and leadership, in particular among African youth, were conditioned by the constant need to "prove yourself". Individual struggles were resonant through group affiliations and a notion of resilience that "no matter what you went through or what your educational background is, you can actually do it". The acts of "tuning oneself" were based on these feelings of proving oneself within the Australian society as well as within their own communities:

And it's about the time to prove yourself. Sometimes there are opportunities out there that come out of your bad situation. For example, I'm here today, I went to the University and I'm working (...) So we need to look at that...And also, looking at that and getting opportunity through that and also changing yourself and tune...Like in the music, you tune to the levels. That could be a way of doing things.

One participant recalled an event that happened in the 
school that can be interpreted as an act of "tuning":

I remember once, in year 12 we had this...for English you had to give a presentation and I remember one of the students came up and talked about the Iraqi war and...he was just telling terrible things about Baghdad...And, I could have screamed and yelled at him, but what I did was that I changed my presentation...I didn't talk about this was right this was wrong, but I talked about it from the perspective of a young Iraqi person, when I was a child and what Baghdad meant to me and what it is now and how I could no longer relate to this place because of what happened. So, a lot of people were crying and thanked me and said look we didn't know about this and now we know so much.

This can be, in fact, interpreted as a political act performed by an "everyday maker". The process of "stepping out" and "tuning oneself" to the new environment was not aimed at integration or adaptation as such, but on identifying gaps and voids in the shared national space, and opportunities for a dialogue based on these gaps and voids.

\section{Bringing Things "Back Home"}

Even though we may see participation, engagement and integration as processes controlled by a certain political formation (nation-state, local government area, region, etc.) aiming for a coherent, harmonious community, these processes are not and should not be understood in a linear way. Nor do the acts of "stepping out" and "tuning" represent final "products" of the integration process. Most young people in the study felt that they needed to bring things they learned "back home".

I've done them both (community and outside work) concurrently, but when I started, I started outside. What I did when I came here was that I went to a youth group, after three years when I was here I became a member of the youth group that wasn't specific African (...) and three years later, I start getting into the community.

Participants in the focus groups who "stepped out" and engaged with the cross-cultural sphere outside, often experienced barriers when attempting to return "back home". When engaging with the community by expressing their own points of view, some young people experienced a feeling of hopelessness:

A couple of years ago I could say to you it's about setting example to people in the community by saying...I'm at Uni, I don't do things that we are traditionally meant to do, but I'm still having such a good life, I could have a really good future and sort of encourage them to do that. But now I think...I romanticised it two years ago. Because no, in reality no, no one will do that and you will end up alone.

The feeling of needing to "prove yourself" reappeared in the process of "returning back" to the family or the community:

People have to see what you do. People have to see how you are fond of things. For those who came here with their parents, it's a different story. You have to prove to your parents, so that they trust what you're doing. If you have no parents, you have your community. And you have to prove yourself to the community. And the community, it has high expectations, especially the African community...

High expectations and intergenerational conflicts that young people faced when trying to reconnect with their families and communities do not only reflect the assumed "fixed" nature of families or communities, but the fact that Governments, programmes and services do not recognise the fluid and circular dynamics of participation. Even when young people participate in broader social activities their participation does not necessarily extend back into familial contexts. Yet intergenerational conflict is driven by different expectations in relation to issues of cultural maintenance and transmission as well as family expectations in relation to educational and employment outcomes.

Against the background of the National Youth Strategy, young people identified family units as critical to their health and wellbeing and supporting families was seen as beneficial for young people and the broader society (Australian Government, 2010, p. 10). "Supporting young Australians within their families" also became one of the "priority areas for action" in the Strategy. However, programs aimed at connecting the participation of young people with their families holistically are yet to be designed. Perspectives of young people included in the National Strategy included calls for recognition of differences in opportunities they have and disadvantages they face. Even though programmes focus on "disadvantaged" or "at risk" youth, the explanations of what this means for young people as well as a broader social context are absent.

The data from focus group discussions in this paper reveal a deep cynicism and much criticism of banal calls for participation, often promoted in a predominantly linear and unilateral way. There is little understanding in national agendas such as those focused on social inclusion and multiculturalism and promoted through Government programs, of how migrant youth negotiate the pressures of engagement with the dominant culture on one hand, and their families and local communities on the other. Migrant youth often form a tenuous bridge between two worlds underpinned by 
an inherent tension that is at once insoluble, yet is also, by its nature, a cause for constructive dialogues. And it is through such tensions and conversations that the essence of active citizenship is played out within forms of a performative multiculturalism not constrained by the rhetoric of Governmental policy. As active participation in civic life is linked strongly to citizenship in the literature, this phenomenon shows the limits of the current institutional one-dimensional understanding of citizenship participation.

Nira Yuval-Davis (1997) suggests that focussing on the public sphere as the only site where citizenship is performed (Turner, 1990; Jayasuria, 1990; Pateman, $1989)$ is problematic. She proposes to differentiate between three distinct spheres: state, civil society and the domain of the family, kinship and other primary relationships. Therefore, any comparative theory of citizenship "must include an examination of the individual autonomy allowed to citizens (of different gender, ethnicity, region, class, stage in the life cycle, etc.) vis-à-vis their families, civil society organizations and state agencies" (Yuval Davis, 1997, p. 15). Not only do Government youth services have much to offer; they often work best when they transcend the rigid discursive forms-in which they are confined, so that the youth are given the space of agency to engage with their adopted culture, but also to create a feedback loop between this burgeoning identity and their heritage culture as embedded in their home-life.

Family and community networks are places of comfort, but also places of tensions. The circular process of stepping out, tuning and returning back home is reflective of young people's identities and struggles to belong, and this is an inherently challenging process. For migrant youth in this study, negotiations of belonging were often related to ongoing challenges in positioning oneself vis-à-vis the local and global environments simultaneously. To this end, some (see, e. g., Anthias, 2006) have called for studying positionality rather than identity, because positionality allows one to understand "the lived practices in which identification is practiced and performed". Positionality also addresses the intersubjective, organisational and representational conditions for the existence of identity (Anthias, 2001 , p. 635). One of the participants eloquently expressed this link drawing on his experience:

To me to live in Australia is to live in two worlds. I give Australia fifty per cent and I give my community fifty per cent. I do this because I know I will not get accepted in Australia hundred per cent. It doesn't matter what you do or what you achieve. So, what I do, it's a balance, you know. When I'm with an Australian, I know how I will act and when I am with my people, I know how I will act.

Such tensions sometimes reflect the performative ele- ments within one situation which cannot be entirely erased or translated into another, which means that the smooth transitions between the two are often impossible. The "slippages" in presentation, where "the management of strategies of identity" (Butcher, 2004, p. 226) do not go exactly according to the plan, is where the tensions are created. Yet, these tensions also represent situations where young people begin to form and develop their own agency, negotiate difficulties of belonging constructively and position themselves as genuine "actors of citizenship".

\section{Conclusion}

The desire of migrant youth to step out of their family environments and/or their communities is often coupled with their willingness to embrace their newly adopted "homeland"/place of residence; to be open to engage with the society in which their identity and independence are developing, without necessarily rejecting their cultural heritage. On the contrary, they often wish to transfer their knowledge and to "prove themselves" to their families and communities and in the process, return back home. Showing a different self to the family and the community is accompanied by personal projects of belonging, which permeate migration and settlement, not to mention growing up. Despite this, such personal belonging projects are often fraught with feelings of marginalisation, as this paper shows in the context of African and Arabic-speaking youth in Melbourne. In many cases these feelings are accentuated by structural socioeconomic disadvantages linked to their families, though also rendered even more complex due to the provoked sense of belonging to two-worlds, and equally to none.

As claimants of citizenship, migrant youth often refer to multiculturalism as their space of belonging (Pardy \& Lee, 2011, pp. 300, 305). They act from the internal boundaries of the nation, traverse cultural and social spaces, and balance between their positions. For many young people, multicultural space is not only a space between two worlds; it permeates all spheres of their lives including engagement with the state, civil society as well as family networks. To be an active citizen in the multicultural nation means not only to be strategic in dealing with cultural transactions and being well-positioned in the hybrid space (Noble, Poynting, \& Tabar, 1999); it also requires involvement in family and community spheres. As an active community member, one needs to be present in a variety of spheres.

Comparing multicultural contexts, speaking out and challenging mainstream ideas about families and communities is indeed to act politically, since acting politically is "to express an identity that is both prescribed and subjectively felt" (McNevin, 2011, p. 15). Migrant youth who assert their voices on their own accord through different avenues (social media, specific 
civil society association, or leisure activity) redefine also what it means to be "Australian". By organising open public discussions, leadership programmes, workshops, forums etc. they are not focusing on their sense of exclusion, but claiming and legitimising their feeling of inclusion and belonging. Their "stepping out", in this context, means legitimising their position "within".

This type of agency enables migrant youth to become political agents, instead of being patronised, overlooked, and ultimately disempowered. If this agency is not recognized, the voice of migrant youth is not only subjugated; but their reality as political agents able to adjust, challenge and engender different layers of citizenship will not be recognized. Migrant youth not only have the potential to contribute to, but also to broaden the discursive scope of Australian identity, belonging and the role of the citizen as a political agent of change.

In this way, migrant youth also contest and challenge the nature and the content of national identity. They understand that every concept of community, especially if it relates to regulative political community, includes by default exclusion and that "people who are constructed to be members of other ethnic, racial and national groups, are not considered 'to belong' to the nation-state community, even if formally they are entitled to" (Yuval Davis, 2007, p. 563). They criticize the dominant patterns of exclusion and challenge the view which accepts rather than unsettles the traditional understanding of citizenship. They can challenge some of the traditional views about "active citizenship" by developing reflexive, "project-oriented identities" to signal their presence. They are "doing citizenship" and performing "acts of citizenship" in a manner that is focused on and driven by their individual subjective positions.

The common thread linking migrant youth in their pursuit of social integration is that they all struggle, not first and foremost against something, but within something: within the socio-political system, within the city, within schools and within neighbourhoods. In other words, even though they are positioned within a specific context; they end up oscillating between internal and external spheres within their communities. Belonging to either of the spheres is filled with moral ramifications, as "debt" is incurred towards their families and communities as well as towards their host societies, and needs to be repaid in exchange for the gift of social life (Hage, 2002, pp. 201-205). As Ghassan Hage (2002, p. 204) contends, feelings of indebtedness become most prominent with migration when one leaves the society that offered him or her social life in return for his or her loyalty. But these feelings are not restricted to one communal formation; debt can be incurred also in a society one migrates to. This, as Hage argues, complicates the situation where "while participation in the host community can be seen as repayment of the debt of belonging to it, the same participation can accentuate feelings of guilt towards the original commu- nity" (Hage, 2002, p. 204). Such situation creates a complicated and jumbled situation for migrant youth who are often endowed with the family expectation to deliver promises of a better future in the country of settlement, as well as act as good "guests" and "good citizens" in the country of arrival.

National policies of youth engagement in Victoria and Australia focus on engendering the ability for young people to "step out" of their immediate environments and "engage, create" and "get involved". But such policies generally neglect the capacity of migrant youth to "complete" their "acts of citizenship" by a desire to "bring things back home". Citizenship should not be viewed as a linear, but a circular and contested journey. Indeed, there are many young people who do not desire to be involved in community activities at all. They do not participate in social forums and are not members of organised groups aimed at initiating conversations with "the mainstream". In policy terms, they may be seen as in "need of guidance and control" (Vromen \& Collin, 2010, p. 98), even in need of being assisted in their decision to "step out". The findings of this study, however, would suggest that the success of future policy-making is to recognize the wide spectrum of social and political engagement including the deliberate decision of some young people to resist altogether such activities.

\section{Acknowledgements}

This paper is based on an Australian Research Council Linkage Grant which included two important industry partners namely the Centre for Multicultural Youth and the Australian Red Cross. The authors would like to express their deep gratitude to project co-investigator Zlatko Skrbis as well as project researchers Libby Effeney, Melinda Chiment, Ameera Karimshah and our industry partners Steven Francis, Carmel Guerra, and Soo-Lin Quek for their valuable contributions in organising data collection activities, conducting interviews and initial compilation of research data.

\section{Conflict of Interests}

The authors declare no conflict of interests.

\section{References}

Anthias, F. (2001). New hybridities, old concepts: The limits of culture. Ethnic and Racial Studies, 24(4), 617-641.

Anthias, F. (2006). Belongings in a Globalising and Unequal World: Rethinking Translocations. In N. Yuval Davis, K. Kannabiran, \& U. M. Vieten (Eds.), The Situated Politics of Belonging (pp. 17-32). London, UK: Sage Publications.

Australian Bureau of Statistics. (2011). 2011 Census 
Quick Stats. Retrieved from http://www.censusda ta.abs.gov.au/census_services/getproduct/census/ 2011/quickstat/2GMEL

Australian Government. (2010). National Strategy for Young Australians. Retrieved from http://www. youth.gov.au/sites/Youth/bodylmage/Documents/ NatStrat.pdf

Australian Office for Youth. (2009). Investing in Australia's Young People: A Stocktake of Australian Government Initiatives for Young People. Canberra: DEEWR.

Bang, H. (2005). Among Expert Citizens and Everyday Makers. In J. Newman (Ed.), Remaking Governance: Peoples, Politics and the Public Sphere (pp. 159179). Bristol, UK: The Policy Press.

Bang, H. (2009). "Yes, we can": Identity politics and project politics for a late-modern world. Urban Research \& Practice, 2(2), 117-137.

Bang, H., \& Sørensen, E. (1999). The everyday maker: A new challenge to democratic governance. Administrative Theory \& Praxis, 21(3), 325-341.

Bell, J., Vromen, A., \& Collin, P. (2008). Rewriting the Rules for Youth Participation: Inclusion and Diversity in Government and Community Decision Making. Canberra, Australia: DEEWR.

Bessant, J. (2004). Mixed messages: youth participation and democratic practice. Australian Journal of Political Science, 39(2), 387-404.

Butcher, M. (2004). Universal processes of cultural change: Reflections on the identity strategies of Indian and Australian youth. Journal of Intercultural Studies, 25(3), 215-231.

Centre for Multicultural Youth. (2012). A sustained commitment to multiculturalism in tight budget. Retrieved from http://www.cmy.net.au/Assets/ 2017/1/VicBudgetMR1May2012.pdf

Colic-Peisker, V. (2009). Visibility, settlement success and life satisfaction in three refugee communities in Australia. Ethnicities, 9(2), 175-199.

Dalton, R. J. (2006). Citizen Politics: Public Opinion and Political Parties in Advanced Industrial Democracies. Washington, USA: CQ Press.

Desforges, L., Jones, R., \& Woods, M. (2005). New geographies of citizenship. Citizenship Studies, 9(5), 439-451.

Hage, G. (2002). The Differential Intensities of Social Reality: Migration, Participation and Guilt. In G. Hage (Ed.), Arab Australians Today: Citizenship and Belonging (pp. 192-206). Melbourne, Australia: Melbourne University Press.

Hall, T., Williamson, H. W., \& Coffey, A. (2000). Young people, citizenship and the third way: A role for the youth service? Journal of Youth Studies, 3(4), 461472.

Harris, A., Wyn, J., \& Younes, S. (2010). Beyond apathetic or activist youth: "Ordinary" young people and contemporary forms of participation. Young:
Nordic Journal of Youth Research, 18(1), 9-32.

Isin, E. (2000). Introduction: Democracy, Citizenship and the City. In E. Isin (Ed.), Democracy, Citizenship and the Global City. New York, USA: Routledge.

Isin, E. (2009). Citizenship in flux: The figure of the activist citizen. Subjectivity, 29, 367-388.

Isin, E., \& Nielsen, G. M. (2008). Acts of Citizenship. London, UK, and New York, USA: Zed Books.

Jayasuria, L. (1990). Multiculturalism, citizenship and welfare: New directions for the 1990s. Presented at the 50th Anniversary Lecture Series, Department of Social Work and Social Policy, University of Sydney, Australia.

Kirby, P., \& Bryson, S. (2002). Measuring the Magic: Evaluating and Researching Young People's Participation in Public Decision Making. London, UK: Carnegie Young People's Initiative.

Marsh, D., O'Toole, T., \& Jones, S. (2007). Young People and Politics in the UK. Basingstoke, UK: Palgrave Macmillan.

Marshall, T. H. (1950). Citizenship and Social Class, and Other Essays. Cambridge, UK: Cambridge University Press.

Matthews, H., Limb, M., \& Taylor, M. (1998/1999). Local places and the political engagement of young people: Youth councils as participatory structures. Youth and Policy: The Journal of Critical Analysis, 62, 16-31.

MCEETYA. (2008). Melbourne Declaration on Educational Goals for Young Australians. Australia: Ministerial Council on Employment, Education and youth Affairs.

McNevin, A. (2011). Contesting Citizenship. Irregular Migrants and New Frontiers of the Political. New York, USA: Columbia University Press.

Milbrath, L. W., \& Goel, M. L. (1977). Political Participation: How and Why Do People Get Involved in Politics? Chicago, USA: Rand McNally.

Muir, K., Mullan, K., Powell, A., Flaxman, S., Thompson, D., \& Griffiths, M. (2009). State of Australia's Young People: A Report on the Social, Economic, Health and Family Lives of Young People. Canberra: DEEWR.

Noble, G., Poynting, S., \& Tabar, P. (1999). Youth, ethnicity and the mapping of identity: Strategic essentialism and strategic hybridity among male Arabic speaking youth in south-western Sydney. Communal/Plural, 7(1), 29-44.

Norris, P. (2002). Democratic Phoenix: Reinventing Political Activism. Cambridge, UK: Cambridge University Press.

Pardy, M., \& Lee, J. C. H. (2011). Using buzzwords of belonging: Everyday multiculturalism and social capital in Australia. Journal of Australian Studies, 35(3), 297-316.

Pateman, C. (1989). The Disorder of Women. Cambridge, UK: Polity Press.

Putnam, R. (2000). Bowling Alone: The Collapse and 
Revival of American Community. New York, USA: Simon \& Schuster.

Sampson, R., \& Gifford, S. (2010). Place-making, settlement and well-being: The therapeutic landscapes of recently arrived youth with refugee backgrounds. Health \& Place, 16(1), 116-131.

Smith, B., \& Reside, S. (2010). Boys, You Wanna Give Me Some Action? Interventions into Policing of Racialised Communities in Melbourne. Melbourne, Australia: Victorian Legal Services Board.

Turner, B. (1990). Outline of a theory on citizenship. Sociology, 24(2), 189-218.

Verba, S., \& Nie, N. H. (1972). Participation in America: Political Democracy and Social Equality. London, UK: Harper \& Row.

Victorian Government. (2012). Victorian Government's Youth Statement. Melbourne, Australia: Victorian Government.

Vinken, H. (2005). Young People's Civic Engagement:
The Need for New Perspectives. In H. Helve \& G. Holm (Eds.), Contemporary Youth Research (pp. 147-157). Aldershot, UK: Ashgate.

Vromen, A. (2003). "People try to put us down...": Participatory citizenship of "Generation X". Australian Journal of Political Science, 38(1), 79-99.

Vromen, A., \& Collin, P. (2010). Everyday youth participation? Contrasting views from Australian policymakers and young people. Young: Nordic Journal of Youth Research, 18(1), 97-112.

Yuval Davis, N. (1997). Women, citizenship and difference. Feminist Review, 57, 4-27.

Yuval Davis, N. (2007). Intersectionality, citizenship and contemporary politics of belonging. Critical Review of International Social and Political Philosophy, 10(4), 561-574.

Wyn, J., \& Woodman, D. (2006). Generation, youth and social change in Australia. Journal of Youth Studies, 9(5), 495-514.

\section{About the Authors}

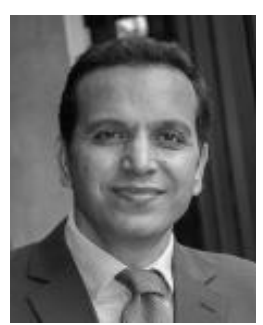

\section{Dr. Fethi Mansouri}

Alfred Deakin Professor Fethi Mansouri holds a UNESCO Chair in comparative research on cultural diversity and social justice, and is the Director of the strategic research Centre for Citizenship and Globalisation at Deakin University, Australia. He is the editor of the Journal of Intercultural Studies (Routledge) and a global expert advisor to the United Nations (Alliance of Civilizations). Professor Mansouri's 2004 book Lives in Limbo: Voices of Refugees under Temporary Protection was short-listed for the 2004 Human Rights Medals and Awards.

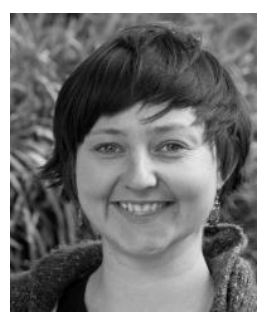

\section{Dr. Maša Mikola}

Maša Mikola teaches in international studies and anthropology at RMIT University and the University of Melbourne. Her research interests are in urban anthropology, political interventions, and theories of power and citizenship. She was a Research Fellow at Deakin University between 2011 and 2013 working on the project "Social Networks, Belonging and Active Citizenship among Migrant Youth in Australia". 